\title{
Hysteroscopic treatment of cervical pregnancy: case report
}

\section{Aarón Jiménez Valdez ${ }^{1 *}$, Sara Elia Hernadez Flores ${ }^{2}$, Jorge Arturo Barbabosa Vilchis ${ }^{3}$, Claudia Meixueiro Calderon ${ }^{4}$}

\author{
${ }^{1}$ Department of Obstetrics and Gynecology, Naval Medical Center, Mexico \\ ${ }^{2}$ Chief of Tococirugia, Naval Medical Center, Mexico \\ ${ }^{3}$ Department of Gynecology, Naval Medical Center, Mexico \\ ${ }^{4}$ Department of Pathology, Naval Medical Center, Mexico
}

Received: 13 February 2020

Accepted: 19 February 2020

*Correspondence:

Dr. Aarón Jiménez Valdez,

E-mail: palencia1213@hotmail.com

Copyright: (C) the author(s), publisher and licensee Medip Academy. This is an open-access article distributed under the terms of the Creative Commons Attribution Non-Commercial License, which permits unrestricted non-commercial use, distribution, and reproduction in any medium, provided the original work is properly cited.

\begin{abstract}
Of ectopic pregnancies, cervical implantation pregnancy is an exceptional entity, corresponding to less than $1 \%$ of ectopic pregnancies. With an incidence calculated at 1: 2500 to $1: 12,000$ pregnancies. The risk factors for cervical pregnancy are the same as for other ectopic pregnancies. This entity, a difference from tubaric pregnancy where bleeding is within the peritoneal cavity, the main risk is incoercible vaginal bleeding, which usually ends in a hysterectomy, which limits the reproductive future of patients. There are currently no established criteria for candidates for medical versus surgical treatment. This case reports a case of cervical ectopic pregnancy, treated with Methotrexate, and culminating with hysteroscopy resection.
\end{abstract}

Keywords: Cervical implantation, Ectopic pregnancies, Hysteroscopy, Methotrexate

\section{INTRODUCTION}

The cause of cervical pregnancy is still unknown. It occurs when the zygote is implanted in the path of the cervical canal. ${ }^{1,2}$ It is an exceptional entity, corresponding to less than $1 \%$ of ectopic pregnancies. With an incidence calculated at $1: 2500$ to $1: 12,000$ pregnancies. Early diagnosis is important, to avoid incoercible bleeding and propose a treatment with a higher probability of success. ${ }^{3}$ Cervical pregnancy is sometimes asymptomatic, and is found as an ultrasound finding. The diagnosis of cervical pregnancy is clinical, with the support of transvaginal ultrasound. Transvaginal ultrasound can be performed safely in a patient with a cervical location pregnancy. ${ }^{4}$ This study improves the diagnosis in $81 \%$ of cases.

\section{Management}

A first-line management is Methotrexate for stable patients, and immediate surgery for patients with abundant sacredness accompanied by hemodynamic instability. At present there are no established criteria for the use of Methotrexate in cervical pregnancy, the evidence is limited to case reports and small series. ${ }^{5}$ Previously, evacuation was performed with instrumented uterine curettage, causing incoercible bleeding, which required to be controlled with different methods such as tamponade, cerclages or impingement, with unsatisfactory results that concluded in surgical treatment with hysterectomy. ${ }^{6-8}$

This work describes the medical treatment with multidose Methotrexate, with serial control of chorionic gonadotropin hormone $(\mathrm{CGH})$, and culminating with hysteroscopic resection.

\section{CASE REPORT}

24-year-old patient, originally and resident of Manzanillo, Colima, México, psychologist, single. 
Heredofamilial history without relevance for the condition, blood group $\mathrm{O}$ positive, chronic degenerative diseases and allergies denied, appendectomy open at 10 years, menarche at 12 years with regular cycles at the rate of $28 \times 3$ days, onset of sexual life at 15 years, number of sexual partners: 7 , family planning method: condom, one pregnancy.

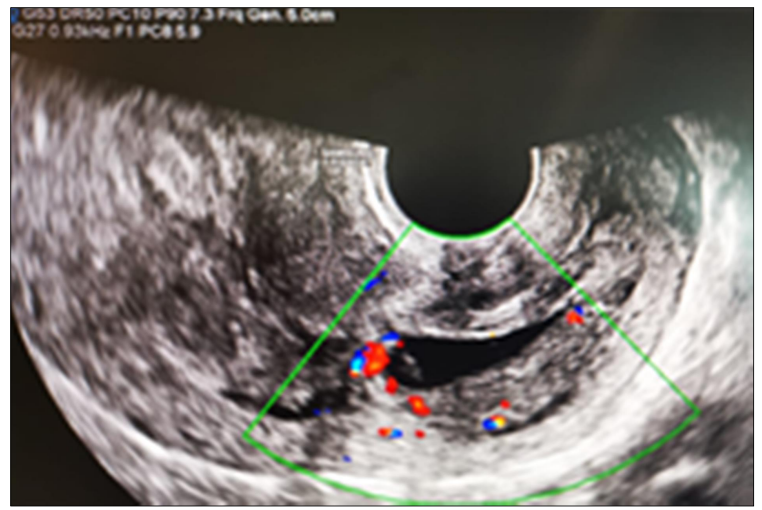

Figure 1: Transvaginal ultrasound showing gestational case of cervical implantation.

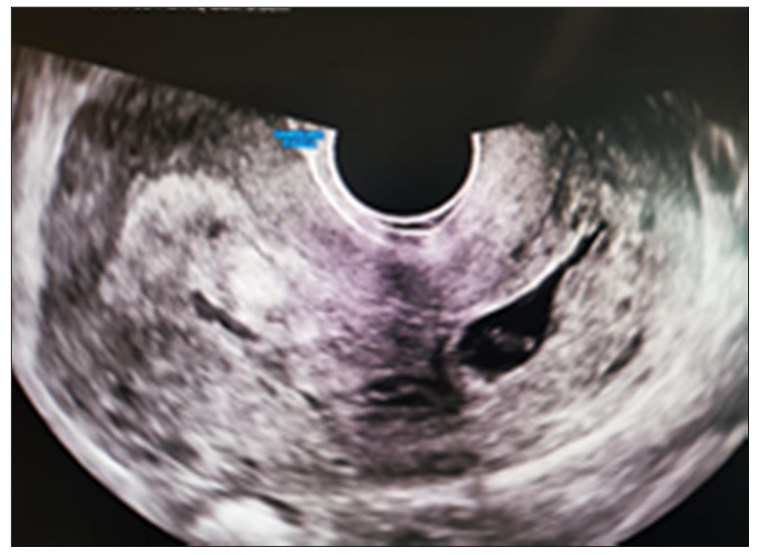

Figure 2: Gestational cervical implantation sac.

Go to the emergency department in a second level unit, with little transvaginal bleeding not corresponding to your period, with amenorrhea of 5 weeks, without abdominal pain. It is managed as an evolving abortion by documenting gestational sac in the cervical canal, initiating treatment with misoprostol $800 \mathrm{mcg}$ in 3 sublingual doses, the patient does not have significant vaginal bleeding or cervical modifications, a control ultrasound is performed where gestational sac persists at the cervical level, suspecting in an ectopic pregnancy of cervical location, so it is referred to Naval Medical Center, based in Mexico city.

Upon arrival at this center on January 15, 2020, transvaginal ultrasound is performed where the uterus is shown with $13 \mathrm{~mm}$ endometrial thickening, presence of a $14 \mathrm{~mm}$ gestational sac attached to the posterior fornix, with a $4 \mathrm{~mm}$ embryonic echo without evidence of cardiac scintillation, sac $2.2 \mathrm{~mm}$ vitelline (Figure 1), right ovary with $26 \times 26 \mathrm{~mm}$ ovoid image suggestive of corpus luteum. The quantitative $\mathrm{CGH}$, beta subunit, is reported in figures of 66,996 mUI / $\mathrm{ml}$. In a second assessment, at 7.1 weeks gestation, a quantitative $\mathrm{CGH}$, beta subunit of $63984 \mathrm{mUI} / \mathrm{ml}$ is reported. The diagnosis of cervical pregnancy is corroborated with a second control ultrasound on January 17, 2020 (Figure 2), so patient and family are informed, and prior informed consent is decided hospital admission and initiation of medical treatment with methotrexate at a dose of $1 \mathrm{mg} / \mathrm{kg} /$ day IV, on days $1,3,5,7$, with supportive treatment with folinic acid on days $2,4,6,8$. Laboratory analysis prior to initiation of treatment, with the following report: Hemoglobin 13.1, hematocrit $38 \%$, platelets 257,000 , leukocytes $9,500 \mathrm{~mm}^{3}$, serum glucose $87 \mathrm{mg} / \mathrm{dl}$, creatinine $0.49 \mathrm{mg}$, total bilirubin $0.40 \mathrm{mg}$, direct $0.1 \mathrm{mg}$, indirect $0.3 \mathrm{mg}$, TGO $16 \mathrm{IU} / \mathrm{L}$, TGP $13.1 \mathrm{IU} / \mathrm{L}$.

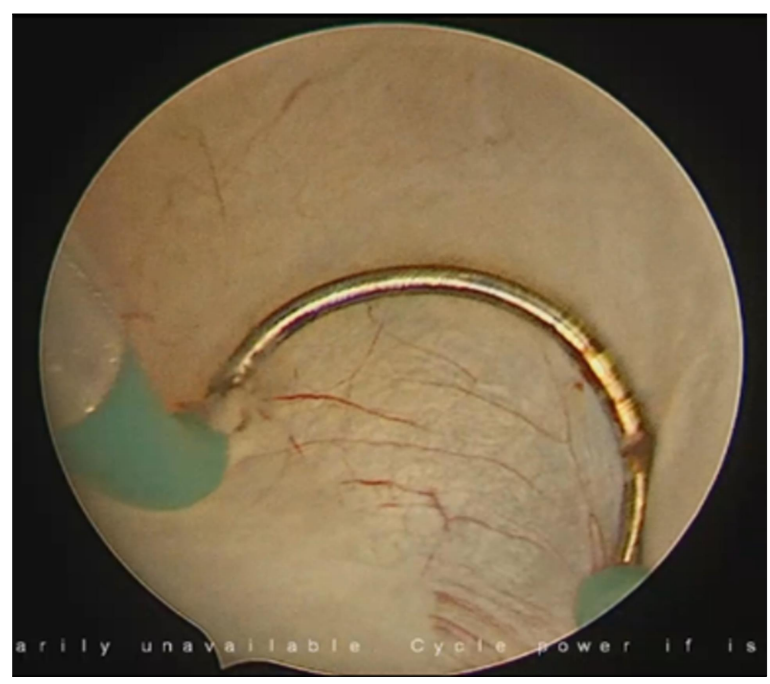

Figure 3: Hysteroscopic resection of cervical gestational sac.

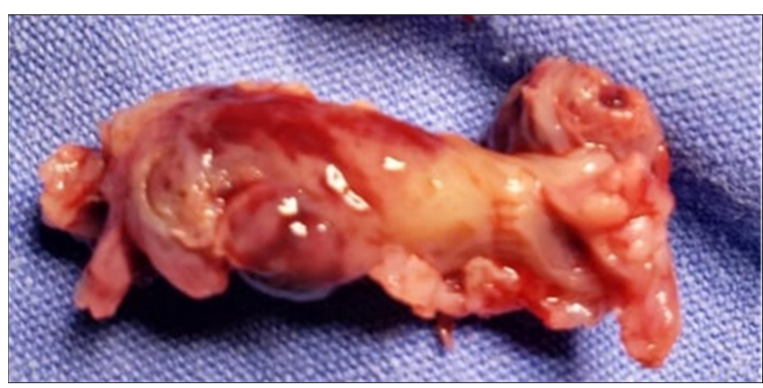

Figure 4: Macroscopic appearance of cervical ectopic pregnancy.

A total 48 hours after the first dose of Methotrexate, a quantification of $\mathrm{HGC}$ of $45,929 \mathrm{mUI} / \mathrm{ml}$ is obtained. Therefore, medical treatment is continued on days 3.5 and 7 , obtaining a quantification of $\mathrm{HGC}$ prior to a 
surgical procedure of $25,822 \mathrm{mUI} / \mathrm{ml}$. On January 25 , 2020 hysteroscopy is performed with access by vaginoscopy, with $5.5 \mathrm{~mm}$ Betochi equipment (Karl Storz), with $0.9 \%$ physiological solution, installed with a Hamou II pump, with flow of $200 \mathrm{ml}$ per minute and pressure of $100 \mathrm{mmHg}$, suction of 0.2 barr. Cervix with permeable external and internal orifice is located, organized material compatible with gestational sac implanted in posterior aspect of the cervix is observed. Implantation zone resection is performed with $5.8 \mathrm{~mm}$ bipolar resect or (mini resectoscope), with coagulation of the implantation site of the gestational sac (Figure 3). As soon as the piece was completely resected, it was extracted from the cervical canal with curved uterine forceps, in a second surgical time an endouterine manual aspiration was obtained obtaining moderate endometrial material, a minimum trans operative bleeding was reported. The patient course with adequate postoperative evolution, hemodynamically stable, tolerating ambulation and orally 12 hours after the procedure, being discharged at 48 hours.

Upon discharge on January 27, 2020 with a report of leukocyte laboratories of $9,100 \mathrm{~mm}^{3}, \mathrm{Hb} 9.5 \mathrm{~g}$, platelets 202,000, neutrophils 83.2\%, quantitative HGC, beta subunit of $2,866 \mathrm{mUI} / \mathrm{ml}$. On February $5^{\text {th }}$, a new quantitative $\mathrm{HGC}$ is performed, a $138 \mathrm{mUI} / \mathrm{ml}$ beta subunit and a control ultrasound with a $9 \times 5 \times 5 \mathrm{~cm}$ uterus report, a $3.8 \mathrm{~mm}$ endometrial echo, both of which are annexes of normal ultrasound characteristics.

The macroscopic aspect of cervical pregnancy can be seen in Figure 4, the histopathological report was as follows: chorial villi of the first trimester with intermediate trophoblast (implantation site).

\section{DISCUSSION}

Medical treatment with Methotrexate in conjunction with hysteroscopic resection, can be a viable management in patients with cervical location ectopic pregnancy. Currently, there are no established guidelines to determine which patients are candidates for such management, considering quantitative HGC level, beta subunit, gestational sac size or caudal skull length if present. $^{3,4}$ The early diagnosis of this entity is a priority to initiate adequate management and provide the patient with a lower risk of morbidity as far as radical surgical treatment is concerned. ${ }^{1}$
Funding: No funding sources Conflict of interest: None declared

Ethical approval: Not required

\section{REFERENCES}

1. Brady PC. New evidence to guide ectopic pregnancy diagnosis and management. Obstet Gynecol Surv. 2017;72(10):618-25.

2. Bielak A, Hincz P, Brot A, Wojciechowska E, Borowski D, Kozarzewski M, et al. Cervical ectopic pregnancy: a case report. Ginekologia Polska. 2006;877(11):881-4.

3. Anate M, Ismaila GA. Cervical ectopic pregnancy: a case report. West African J Med. 1996;15(2):123-5.

4. Levin G, Dior UP, Shushan A, Gilad R, Benshushan A, Rottenstreich A. Risk factors for recurrent ectopic pregnancy following single-dose methotrexate treatment. Eur J Contracept Reprod Health Care. 2019;24(4):294-8.

5. Yang C, Cai J, Geng Y, Gao Y. Multiple-dose and double-dose versus single-dose administration of methotrexate for the treatment of ectopic pregnancy: a systematic review and meta-analysis. Reproduct Bio Med Online. 2017;34(4):383-91.

6. Ohannessian A, Crochet P, Courbiere B, Gnisci A, Agostini A. Methotrexate treatment for ectopic pregnancy after assisted reproductive technology: A case-control study. Gynecol Obstet Fertil. 2016;44(6):341-4.

7. Marret H, Fauconnier A, Dubernard G, Misme H, Lagarce L, Lesavre $M$, et al. Overview and guidelines of off-label use of methotrexate in ectopic pregnancy: report by CNGOF. Eur J Obstet Gynecol Reprod Biol. 2016;205:105-9.

8. Piccioni MG, Framarino-Dei-Malatesta M, Polidori NF, Marcoccia E. Cervical ectopic pregnancy treated with systemic methotrexate and following successful term pregnancy: case report. J Obstet Gynaecol. 2015;35(6):654-5.

Cite this article as: Valdez AJ, Flores SEH, Vilchis JAB, Calderon CM. Hysteroscopic treatment of cervical pregnancy: case report. Int J Reprod Contracept Obstet Gynecol 2020;9:1710-2. 